\title{
Finding an Optimum Period of Oxidative Heat Treatment on SS 316 Catalyst for Nanocarbon Production from LDPE Plastic Waste
}

\author{
Praswasti P.D.K. Wulan", Satrio Bimo Wijardono" \\ ${ }^{\#}$ Department of Chemical Engineering, Faculty of Engineering, University of Indonesia, Depok, 16424, Indonesia \\ E-mail: praswasti.pdk.wulan@gmail.com
}

\begin{abstract}
Plastic waste accumulation has become a major health and environmental problems in many parts of the world. Many efforts have been taken to reduce the accumulation, one of which is to convert it into more useful products, such as CNT. CNT have been used for several products to enhance its properties. In this work, Low-Density Polyethylene (LDPE) plastic waste was used as a feed to produce CNT with the help of wired mesh stainless steel type 316 serving as the catalyst. The stainless steel was pretreated by applying heat under an oxidative environment at $800^{\circ} \mathrm{C}$. The time of the pretreatment was varied from $0,1,5,10$, and 20 minutes to determine the relationship between the period of the pretreatment and the produced CNT quality. The collected nanocarbons were characterized by using XRD, SEM-EDX, TEM, and TGA. It was discovered that CNT was formed from the pretreated catalyst. The best result was obtained from the 10 minutes pretreatment shown by the formation of buckling and continuous growth CNT having an evenly spread carbon with a mean CNT diameter of $7.70 \mathrm{~nm}$, carbon percentage up to $93.3 \%$, and oxidation temperature up to $5^{\circ} 0^{\circ} \mathrm{C}$.
\end{abstract}

Keywords - CNT; LDPE; oxidative heat treatment; SS 316

\section{INTRODUCTION}

Issues regarding plastic waste accumulation are becoming a most discussed topic due to its effect on health and environment. For example, a massive accumulation of plastic waste such as plastic caps, bottles, bags, etc. in the sea has proven to be a severe impediment for the secure existence of marine inhabitants. Another menace the plastic waste can cause is an appropriate habitat for parasites and extortionists under a humid and favorable ambiance for such microorganism to grow. Not only its presence that causes problems, but also its pull out. Until today, careful treatment is needed to treat plastic waste so it can't harm the environment. Plastic waste can't be directly burned because it can produce harmful chemicals like dioxin and furan. It also can't be directly buried because chemicals composing the plastic may leach into the soil and contaminate ground water.

LDPE is one of the type of plastic that is commonly found as waste. This is due to the fact that LDPE is a type of plastic that has high demand, especially in several developing countries like Indonesia, and is usually found as plastic bags. Because of the high demand, it is estimated that 445,000 tons of LDPE are produced each year. Moreover, reference stated that around $60 \%$ of the plastic waste produced across the globe is LDPE, making it clearer that LDPE is present in myriad. On the one hand, carbon nanotube (CNT) could be synthesized from plastic waste by using various methods, such as pyrolysis [2]-[4], [10] and flame synthesis [5]-[7]. LDPE is suitable as feed to produce CNT due to its high carbon content, which is up to $85.6 \%$-wt [9]. Therefore, LDPE plastic waste can be treated to reduce its accumulation whilst gaining its economic value by using it as a feed to produce CNT. 


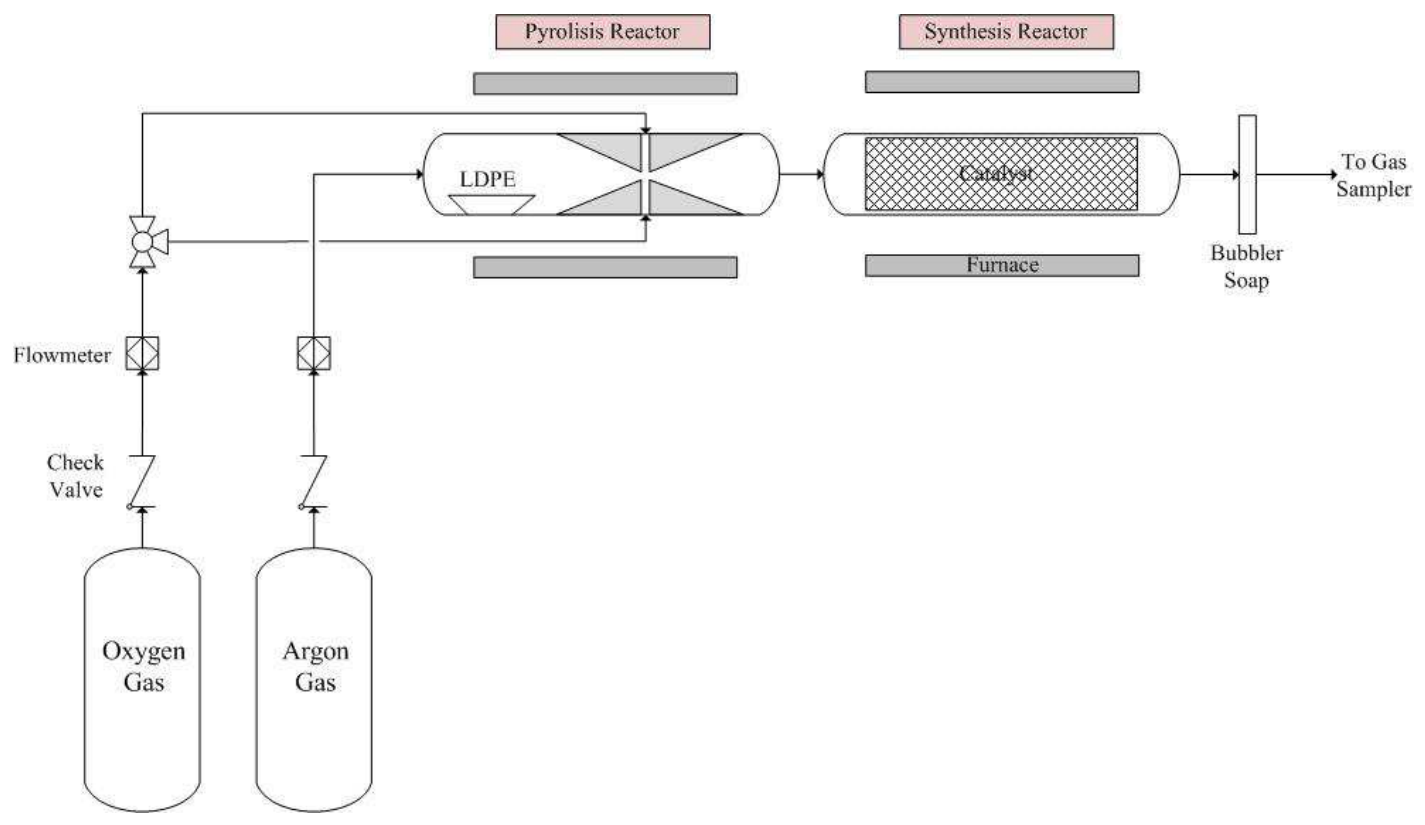

Fig. 1 Scheme of the CNT synthesis system

On the other hand, CNT production is sometimes restrained due to catalyst factor. Most of the time, difficult techniques, and expensive materials are used to prepare a suitable catalyst for CNT growth, e.g. impregnation method [3], [4]. A simpler method like acid etching [8] uses a dangerous and harmful substance, which is concentrated $\mathrm{HCl}$. Such factors have commenced the search of the new catalyst with simpler, cheaper, and safer preparation. It has been proved that stainless steel type 316 (abbreviated as SS 316 from now on unless stated otherwise) is able to become a catalyst for CNT growth due to its high Fe content [10]. However, the alloy layer in every stainless steel, that composes the $\mathrm{Fe}$ is covered by a passive layer functioning as corrosion prevention in stainless steel. To make SS 316 activated as catalyst, pretreatment is required to breach the passive layer. One of the easiest ways to do that is by applying heat on SS 316 in a short amount of time under oxidative environment, or oxidative heat treatment. The process is initiated by oxygen dissolution in the surface of the stainless steel until its saturation point at high temperature. Then, the oxygen will diffuse to the alloy by the effect of the concentration gradient. Inside, oxygen will react with the alloy, yielding an oxide substance that will be precipitated on the surface. Precipitation will occur until the base metal forms scales [11]. Not only capable of breaching the outer layer of the stainless steel but oxidative heat treatment is also capable of making grains on its surface, hence increasing its roughness. It has been reported elsewhere that increase in surface roughness affects the yield of the obtained nanocarbon [10].

In this work, CNT was synthesized from LDPE plastic waste with the help of SS 316 serving as the catalyst using a two-stage reactor with venture system as shown in Fig. 1. SS 316 was pretreated by using oxidative heat treatment with air was used as the oxidizing agent. Pretreatment of SS 316 was done to breach the passive layer of the stainless steel, hence uncovering the metal alloy layer that would later become the catalyst for CNT growth. The time of the pretreatment was varied from $0,1,5,10$, and 20 minutes to determine the relationship between the period of the pretreatment and the produced CNT quality. The collected CNT are characterized using XRD, SEM-EDX, TEM, and TGA to help to determine the optimum period of the pretreatment. The effluent gas is also analyzed using GC to see the effect of oxidative heat treatment towards the catalytic activity of SS 316.

\section{MATERIALS AND METHOD}

\section{A. Oxidative Heat Treatment}

Wired mesh SS 316 (mesh size: 150) was cut into pieces of $10 \mathrm{~cm} \times 30 \mathrm{~cm}$. The pieces were then rolled and cleaned using isopropyl alcohol by mechanical application. Cleaned SS 316 were then placed in a furnace and were heated at $800^{\circ} \mathrm{C}$. The heating period was varied from $1,5,10$, and 20 minutes. After it reached the desired period, the stainless steels were quickly removed from the furnace to room temperature for cold air quenching. The resulting stainless steels after pretreatment is shown in Fig. 2.

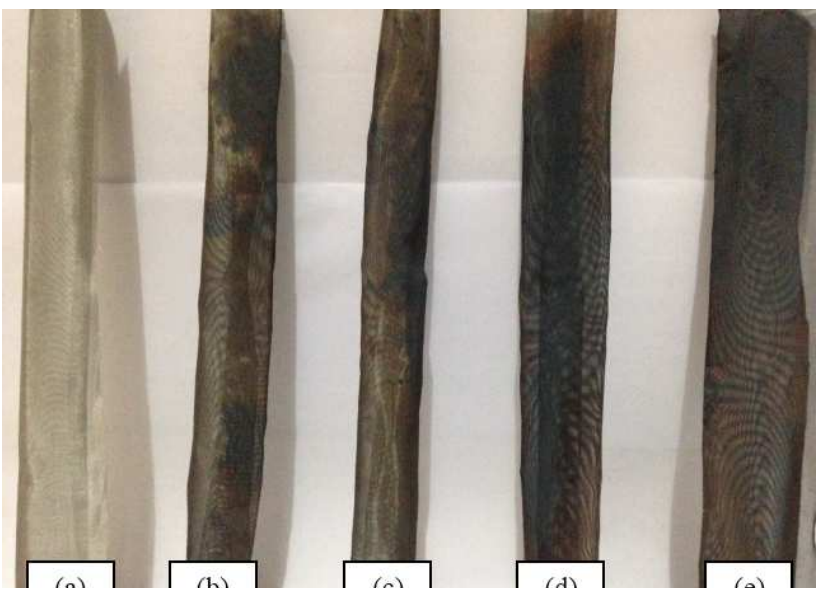

Fig. 2 SS 316 (a) without pretreatment, (b) 1 minute, (c) 5 minutes, (d) 10 minutes, and (e) 20 minutes of pretreatment 


\section{B. CNT Synthesis}

LDPE plastic waste was cut into $2 \mathrm{~cm} \times 2 \mathrm{~cm}$ and weighed to $10 \mathrm{~g}$. The samples were then placed in a boat inside the pyrolysis reactor, and SS 316 were placed in the synthesis reactor. After all of the equipment was set, the synthesis reactor's furnace was turned on, and the temperature was set to $800^{\circ} \mathrm{C}$. In the following 10 minutes, the pyrolysis reactor's furnace was turned on, and the temperature was set to $250^{\circ} \mathrm{C}$. After the pyrolysis reactor's furnace had reached the desired temperature, the system was held for 20 minutes. The process was repeated every increment of $100^{\circ} \mathrm{C}$ until it reached $450^{\circ} \mathrm{C}$. Argon gas was used as a carrier gas flowed at $100 \mathrm{ml} /$ minutes. Oxygen gas was mixed with the pyrolyzed gas from LDPE at the venture to create flame flowed at $33.3 \mathrm{ml} /$ minutes. Oxygen was flowed into the system by the time the temperature of pyrolysis reactor reached $250^{\circ} \mathrm{C}$. After 1 hour of reaction (counted from 1 hour after the pyrolysis reactor's temperature reached $450^{\circ} \mathrm{C}$ ), the oxygen gas was turned off. The system was cooled down afterwards. Scheme of the system is shown in Fig. 1.

\section{Characterization}

The collected nanocarbon was characterized by using XRD (Shimadzu X-Ray Diffraction 7000 Maxima) to determine the formation of CNT based on the sample's crystallinity. SEM-EDX (SEM-EDX Carl Zeiss Bruker Type EVO MA10) was used to determine the morphology and the composition of the collected nanocarbon. Elemental mapping was also done by using this instrument. TEM (TEM FEI Tecnai G2 SuperTwin) was used to determine the morphology of the CNT. TGA (TA Instrument Q50) was also performed to determine the purity of the sample based on its oxidation temperature. The gas effluent from the reactor is also collected to be further analyzed using GC (GC TCD Bruker 436).

\section{RESULTS AND DISCUSSION}

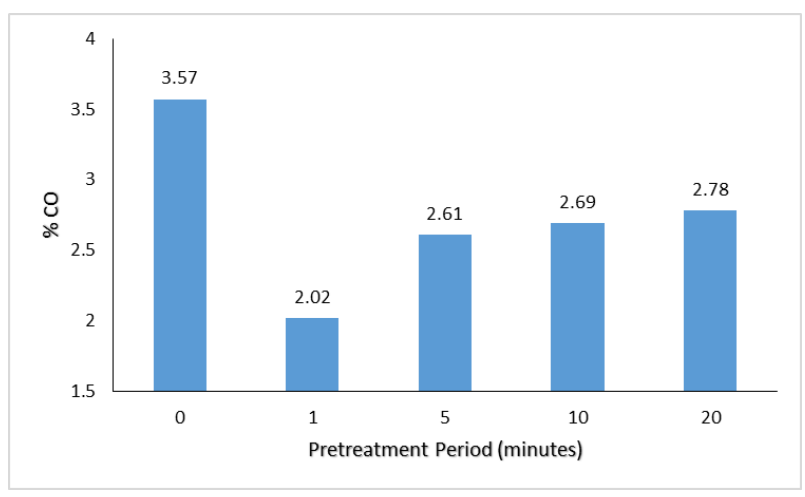

Fig. 3 Effluent CO concentration
TABLE I

YIELD OF COLLECTED CNT

\begin{tabular}{|c|l|l|l|c|}
\hline $\begin{array}{l}\text { Pretreat } \\
\text { ment } \\
\text { period } \\
\text { (minutes) }\end{array}$ & $\begin{array}{l}\text { Mass of } \\
\text { nanocarb } \\
\text { on } \\
\text { collected } \\
\text { from } \\
\text { catalyst } \\
(\mathbf{g})\end{array}$ & $\begin{array}{l}\text { Mass of } \\
\text { nanocarb } \\
\text { on } \\
\text { collected } \\
\text { from } \\
\text { reactor } \\
\text { (g) }\end{array}$ & $\begin{array}{l}\text { Total } \\
\text { mass of } \\
\text { nanocarb } \\
\text { on } \\
\text { collected } \\
(\text { g) }\end{array}$ & Yield \\
\hline 0 & 0.21 & 0.84 & 1.05 & $10.5 \%$ \\
\hline 1 & 0.30 & 3.41 & 3.71 & $37.1 \%$ \\
\hline 5 & 0.54 & 2.96 & 3.50 & $35.0 \%$ \\
\hline 10 & 0.60 & 2.80 & 3.40 & $34.0 \%$ \\
\hline 20 & 1.06 & 2.13 & 3.19 & $31.9 \%$ \\
\hline
\end{tabular}

The CO gas concentration in the effluent of the reactor is shown in Fig. 3. CO gas is obtained from flame production in the venturi due to the reaction occurring between pyrolyzed gas from LDPE and oxygen. It is observed that $\mathrm{CO}$ concentration decreases from the system with pretreated catalyst compared to the system with untreated catalyst. This shows that oxidative heat treatment is able to breach the passive layer of stainless steel and uncover the alloy layer, thus making it a catalyst for $\mathrm{CO}$ dissolution to form CNT following Boudard Reaction as shown in (1). From the pretreated catalyst, it is observed that the mass of nanocarbon collected from the catalyst is increasing as the pretreatment period progresses, as shown in Table 1. This shows that oxidative heat treatment is able to make an adequate roughness on the surface of SS 316, making it probable for CNT growth.

The XRD patterns of the collected samples are shown in Fig. 4. From the XRD patterns, it is found that CNT is not formed from the untreated catalyst, shown by the absence of a peak at diffraction angles $26^{\circ}, 43^{\circ}$, and $54.4^{\circ}$ as stated by Mopoung [12]. This is due to the uncovered alloy layer of the stainless steel and inadequate roughness on the surface, making it improbable for CNT to grow. SS 316 also contains Mo [1] to inhibit CNT growth if it stands alone without Co [10]. The XRD pattern also shows the formation of impurities such as $\mathrm{Fe}_{2} \mathrm{O}_{3}, \mathrm{Fe}_{3} \mathrm{O}_{4}, \mathrm{Fe}_{3} \mathrm{C}$, and amorphous carbon. $\mathrm{Fe}_{2} \mathrm{O}_{3}$ is formed because of the interaction between iron and oxygen in high temperature, resulting in hightemperature corrosion. A similar occurrence is also observed in the formation of $\mathrm{Fe}_{3} \mathrm{O}_{4}$ in much lower selectivity. However, Hayes and Grieveson reported that $\mathrm{Fe}_{3} \mathrm{O}_{4}$ reacted with $\mathrm{CO}$ through the reaction shown in (2) [13]. $\mathrm{Fe}_{3} \mathrm{C}$ is formed by the interaction of $\mathrm{Fe}$ and carbonaceous gas in very low selectivity. Amorphous carbon is formed due to soothing formation on the catalyst caused by the termination phase in CNT growth and/or ungraphitized carbon forming as aggregates.

$$
\begin{gathered}
2 \mathrm{CO}_{(g)} \rightarrow 2 \mathrm{C}_{(s)}+\mathrm{CO}_{2_{(g)}} \\
3 \mathrm{Fe}_{2} \mathrm{O}_{3}+\mathrm{CO} \rightarrow 2 \mathrm{Fe}_{3} \mathrm{O}_{4}+\mathrm{CO}_{2}
\end{gathered}
$$




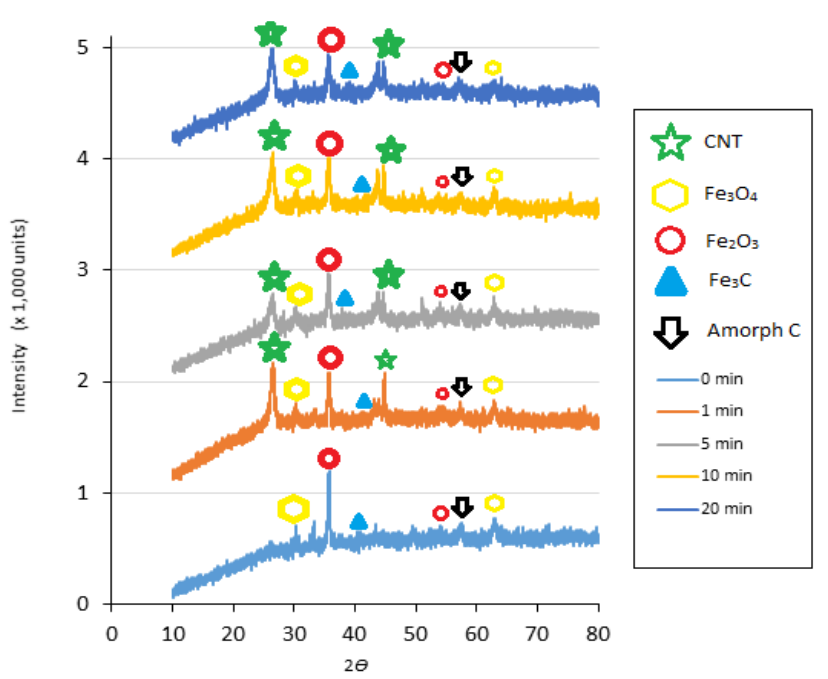

Fig. 4 XRD patterns of collected nanocarbons

The obtained XRD pattern is then used for quantitative analysis by calculating the CNT's mean crystalline size using Scherrer Equation. Reference [14] stated that Scherrer constant of 0.9 is used for CNT crystalline calculation. The calculated crystalline size is shown in Table 2. An escalation in the crystalline size is observed in the CNT obtained from the 20 minutes catalyst pretreatment. This shows the formation of aggregates in the sample caused by entanglement of neighboring CNT during the growth phase and/or ungraphitized carbon. This mechanism is as proposed by [15]. The formation of aggregates and/or ungraphitized carbon is observed further by using elemental mapping of carbon shown in Fig. 6. Aggregates and/or ungraphitized carbon are indicated by red clod formation.

TABLE II

CNT MEAn CRYSTALLINE Size CALCUlation

\begin{tabular}{|c|c|}
\hline $\begin{array}{c}\text { Pretreatment period } \\
\text { (minutes) }\end{array}$ & $\begin{array}{c}\text { Mean crystalline size } \\
\text { (nm) }\end{array}$ \\
\hline 1 & 8.48 \\
\hline 5 & 7.67 \\
\hline 10 & 7.70 \\
\hline 20 & 9.09 \\
\hline
\end{tabular}
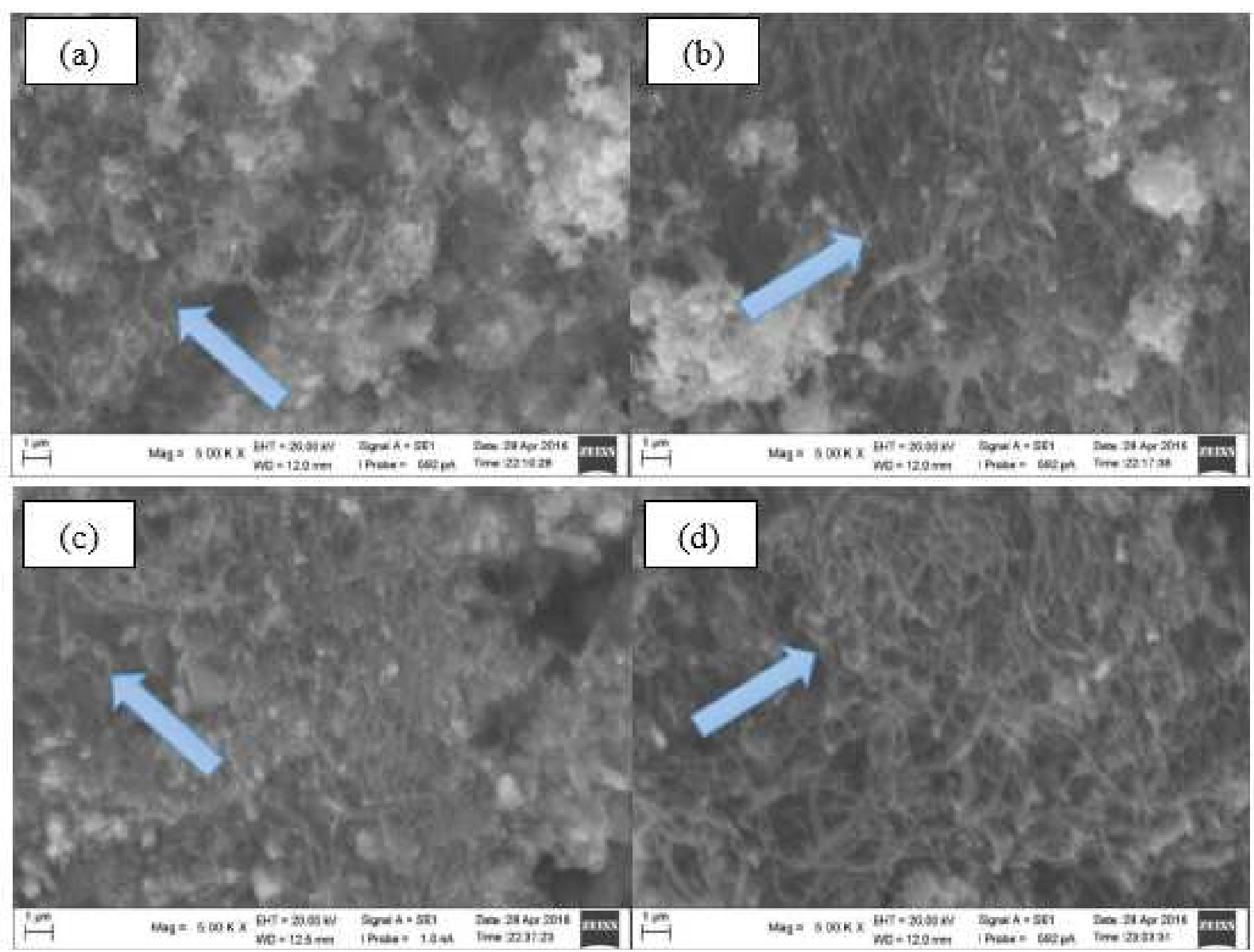

Fig. 5 SEM images of CNT collected from catalysts with (a) 1 minute, (b) 5 minutes, (c) 10 minutes, (d) 20 minutes of Pretreatment 

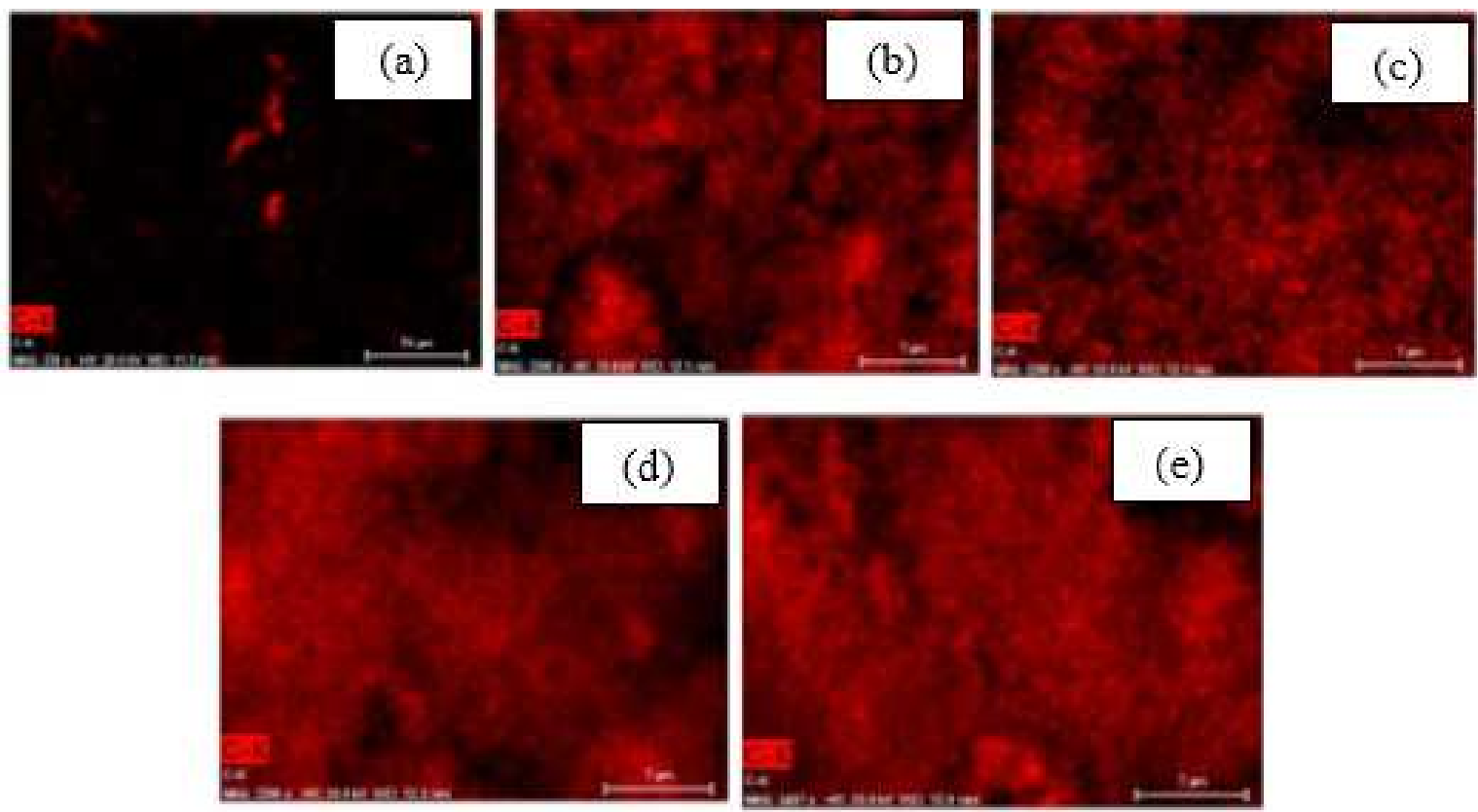

Fig. 6 Elemental mapping of carbon collected from catalysts with (a) 0 minute, (b) 1 minutes, (c) 5 minutes, (d) 10 minutes, (e) 20 minutes of Pretreatment

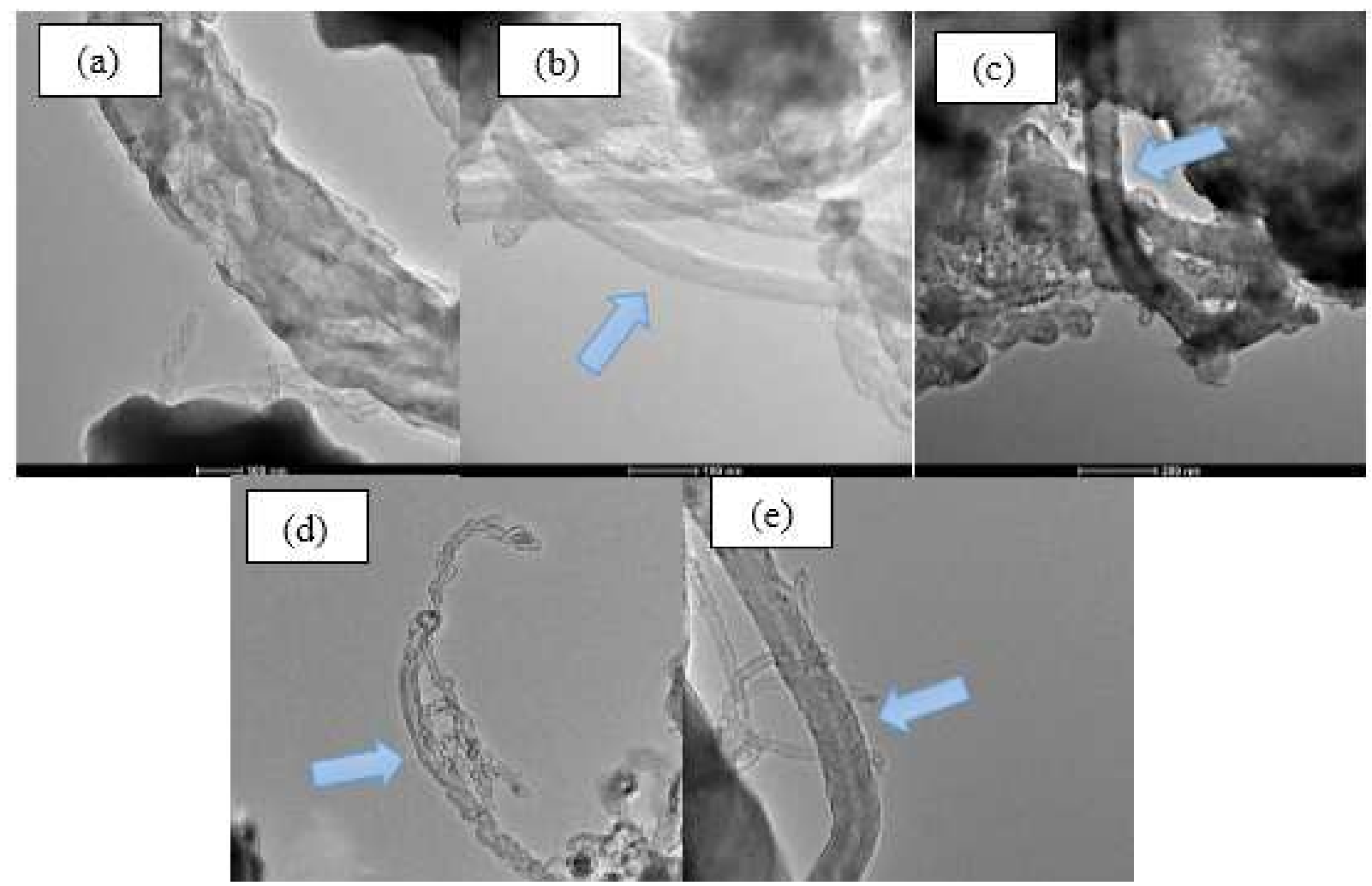

Fig. 7 TEM images of CNT collected from catalysts with (a) 0 minute, (b) 1 minute, (c) 5 minutes, (d) 10 minutes, (e) 20 minutes of Pretreatment

Fig. 5 shows the SEM image of the collected sample. The SEM image of the sample of 0 minutes of pretreatment is not shown due to no sign of CNT formation as indicated by XRD. CNTs are formed from all of the remaining samples indicated by the tubular structure seen in Fig. 5 There are also some flake and clod structures indicating impurities formed during the synthesis. To see the spread of carbon element from all of the other impurities, the elemental mapping is done. Fig. 6 shows the elemental mapping of carbon from all of the collected samples. From Fig. 6, it is also observed that the 10 minutes of pretreatment gives the best CNT quality indicated by an evenly spread carbon compared to the other result obtained. Fig. 6(a) shows the least amount of carbon indicated by few red spots, showing that no CNT is formed as supported by the data collected from XRD. Unlike prior periods of pretreatment, the formation of aggregates is clearly seen from the elemental mapping of nanocarbon obtained from the 20 minutes pretreatment. 
The concentrations of the obtained samples are analyzed using EDX as shown in Table 3. It is observed that the 10 minutes of pretreatment gives the highest carbon concentration, which is up to $93.3 \%$. The result promotes the elemental mapping data obtained where it can be seen that the carbon spreads evenly compared to the other characterized samples. The samples also show some other element rather than carbon, with $\mathrm{Fe}$ and $\mathrm{Ni}$ being the highest metal concentration compared to the other. This shows that $\mathrm{Fe}$ and $\mathrm{Ni}$ are suitable metal catalysts for CNT growth. References [16] reported the same result in their work. The result obtained is also supported by findings reported by [17], stating that those transition metals have the highest carbon solubility. However, high Fe content in the sample obtained from the untreated catalyst shows the $\mathrm{Fe}_{2} \mathrm{O}_{3}$ formation occurring due to high-temperature corrosion. The finding is supported by the XRD patterns obtained from Fig. 4. There are also other elements obtained from the EDX analysis. Metals like $\mathrm{Cr}$ and $\mathrm{Al}$ might become the catalyst for CNT growth, but the presence of small concentration due to low carbon solubility for those metals.

TABLE III

COMPOSITION OF NANOCARBON SAMPLES

\begin{tabular}{|l|r|r|r|r|r|}
\hline & $\begin{array}{c}0 \\
\text { minute }\end{array}$ & $\begin{array}{c}1 \\
\text { minute }\end{array}$ & $\begin{array}{c}5 \\
\text { minutes }\end{array}$ & $\begin{array}{c}10 \\
\text { minutes }\end{array}$ & $\begin{array}{c}20 \\
\text { minutes }\end{array}$ \\
\hline $\mathrm{C}(\%-w t)$ & 13.86 & 86.08 & 73.15 & 93.30 & 83.06 \\
\hline $\mathrm{N}(\%-w t)$ & 0 & 2.35 & 0 & 2.26 & 1.95 \\
\hline $\mathrm{O}(\%-w t)$ & 31.97 & 5.24 & 5.99 & 1.24 & 5.14 \\
\hline $\mathrm{Si}(\%-w t)$ & 5.47 & 0 & 0.08 & 0.28 & 0 \\
\hline $\mathrm{S}(\%-w t)$ & 0 & 0 & 0.19 & 0.16 & 0.06 \\
\hline $\mathrm{Al}(\%-w t)$ & 8.54 & 0 & 0 & 0 & 0 \\
\hline $\mathrm{Cr}(\%-w t)$ & 1,26 & 0 & 1.58 & 0.55 & 0.79 \\
\hline $\mathrm{Fe}(\%-w t)$ & 38.93 & 6.33 & 14.52 & 1.17 & 8.69 \\
\hline $\mathrm{Ni}(\%-w t)$ & 0 & 0 & 1.00 & 0.7 & 0.30 \\
\hline
\end{tabular}

The morphology of the CNT is analyzed by using TEM shown in Fig. 7. From the figure, no CNT is formed from the untreated catalyst, promoting prior results. Multiwalled Carbon Nanotube (MWNT) is observed from the pretreated catalyst indicated by the blue arrow. It is also observed that the CNT possess buckling growth structure due to the interaction between CNT with CNT and/or CNT with catalyst during agglomeration process [15]. When CNT starts to grow, the catalyst morphology will slightly change, therefore making it stretch and forming small clusters. As the growth progresses, the entanglement or interaction between neighboring CNTs and/or CNT with catalyst starts to happen. The interaction will cause bending on the CNT. As the CNT continues to grow by finding empty space, graphitization on the bent part of the CNT's body occurs, therefore making it permanently bend and buckle. It is also observed that the CNT grew by tips growth model, as seen in Fig. 8. The orange arrow indicates the metal nanoparticle that was lifted during the growth of the CNT. As stated by Baker et al., the growth of the CNT follows the VapourSolid-Solid (VSS) Model, where lifting of metal nanoparticle occurs in Precipitation Stage [18]. During the process, there is a weak interaction between the substrate (metal alloy) and catalyst (Fe or Ni nanoparticle), causing the growing carbon to lift the catalyst. The process will stop whenever there is no more gradient of concentration within the surface of the catalyst.

Fig. 9 shows the TGA curve obtained for every sample. From the TGA curve, oxidation temperature can be determined from the sample's mass loss at certain temperature. The oxidation temperature shows the purity of the CNT, where higher oxidation temperature means higher CNT purity [1]. From the data obtained, it is observed that the 10 minutes of catalyst pretreatment gives the best result indicated by high oxidation temperature of CNT which is up to $530^{\circ} \mathrm{C}$. This shows that the produced CNT has the highest purity among all of the samples collected. Other

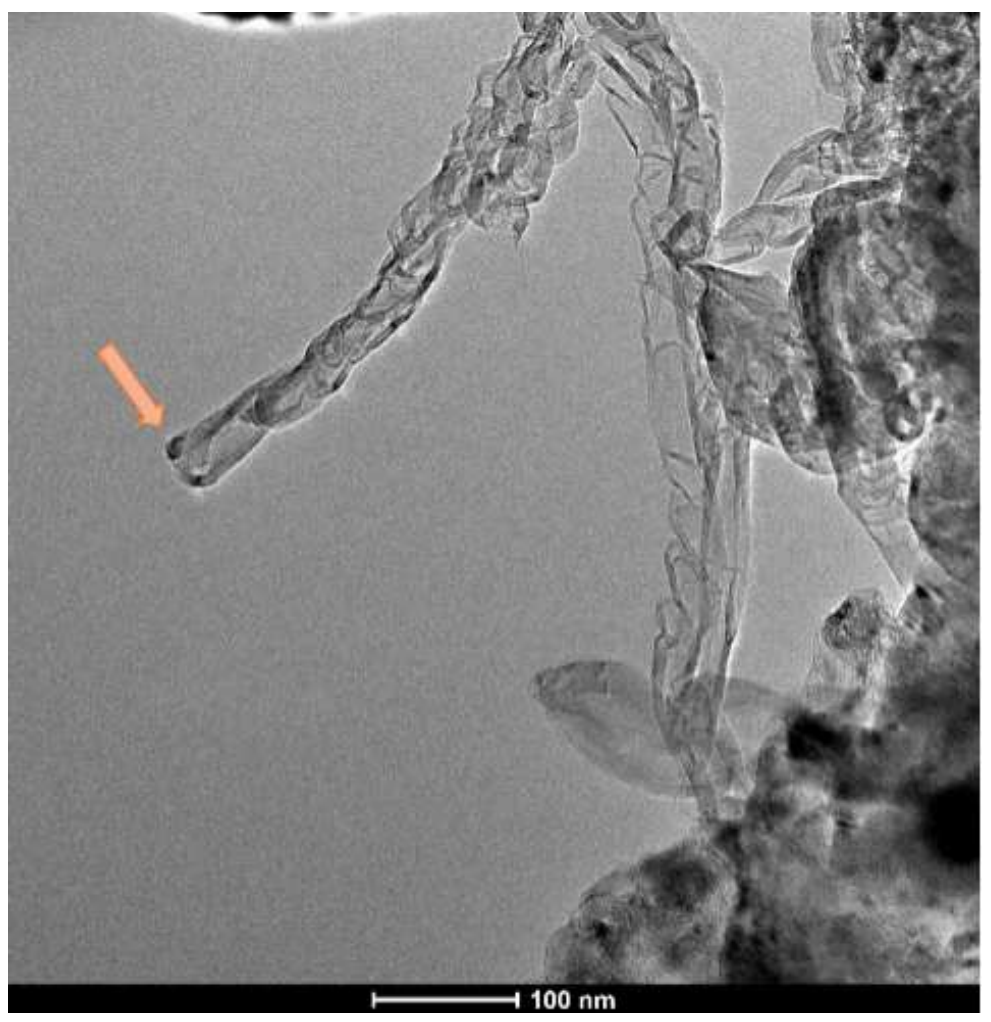

Fig. 8 Observed tips growth of the CNT collected from the sample of 10 minutes pretreatment 
pretreatment periods (1, 5, and 20 minutes) show less number of oxidation temperature, which is $318^{\circ} \mathrm{C}, 528^{\circ} \mathrm{C}$, and $517^{\circ} \mathrm{C}$ respectively. Samples collected from the untreated catalyst shows no mass loss due to the absence of CNT in the sample.

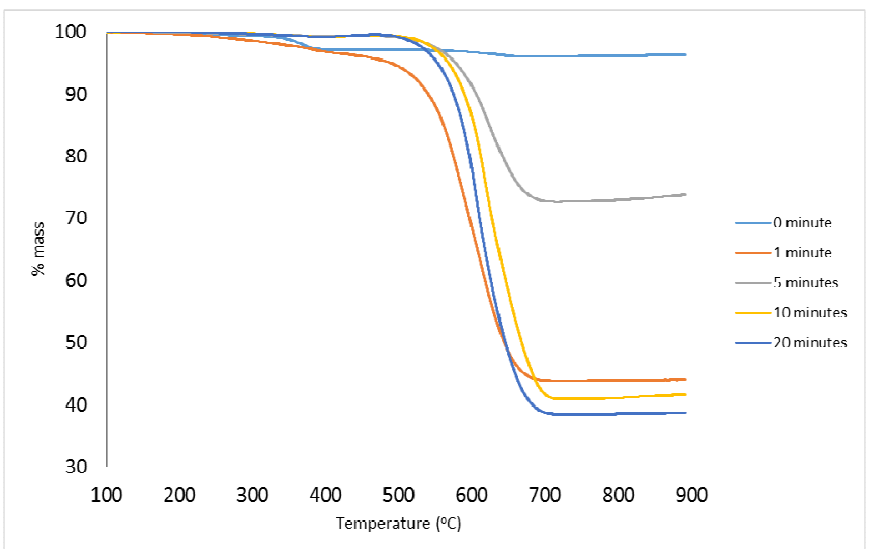

Fig. 9 TGA curves of the collected nanocarbons

\section{CONCLUSIONS}

In summary, it is proved that oxidative heat treatment is able to enhance the catalytic activity of SS 316 to produce CNT from LDPE plastic waste. The optimum period of the pretreatment is 10 minutes indicated by formation of CNT that has an evenly spread carbon having small mean crystalline size (up to nanometer scale), high carbon concentration, and high purity. Using the XRD, SEM-EDX, and TGA to characterize all samples, it is shown that at 10 minutes of pretreatment, the obtained CNT has mean crystalline size of $7.70 \mathrm{~nm}$, carbon concentration up to $93.3 \%$, and oxidation temperature up to $530^{\circ} \mathrm{C}$.

\section{REFERENCES}

[1] C. Zhuo, B. Hall, R. Henning, and Y. Levendis, "Synthesis of carbon nanotubes by sequential pyrolysis and combustion of polyethylene," Carbon, vol. 48, pp. 4024 - 4034, Jul. 2010.

[2] J. Liu, Z. Jiang, H. Yu, and T. Tang, "Catalytic pyrolisis of polypropylene to synthesize carbon nanotube and hydrogen through a two-stage pyrolisis," Polymer Degradation and Stability, vol. 96, pp. 1711 - 1719, Aug. 2011.

[3] J.C. Acomb, C. Wu, and P.T. Wiliams, "Control of steam input to the pyrolisis-gasification of waste plastics for improved production of hydrogen or carbon nanotubes," Applied Catalysis B: Environmental, vol. 147, pp. $571-584$, Sep. 2013.

[4] J.C. Acomb, C. Wu, and P.T. Williams, "Effect of growth temperature and feedstock:catalyst ratio on the production of carbon nanotubes and hydrogen from the pyrolysis of waste plastics," $J$. Anal. Appl. Pyrol., vol. 113, pp. 1 - 8, Sep. 2015.

[5] J.P. Gore and A. Sane, "Flame synthesis of carbon nanotubes," Carbon Nanotubes - Synthesis, Characterization, Applications, Jul. 2011.

[6] C. Zhuo, J.O. Alves, J.A.S. Tenorio, and Y.A. Levendis, "Synthesis of carbon nanomaterials through up-cycling agricultural and municipal solid wastes," Ind. Eng. Chem. Res., vol. 51, pp. 2922 2930, Jan. 2012.

[7] J.O. Alves, J.A.S. Tenorio, C. Zhuo, and Y.A. Levendis, "Use of stainless steel AISI 304 for catalytic synthesis of carbon nanomaterials from solid wastes," J. Mater. Res. Technol., vol. 1, pp. $128-133$, Sep. 2012

[8] C.E. Baddour, F. Fadlallah, D. Nasuhoglu, R. Mitra, L. Vandsburger, and J.L. Meunier, "A simple thermal CVD method for carbon nanotube synthesis on stainless steel 304 without the addition of an external catalyst," Carbon, vol. 47, pp. 313 - 347, Oct. 2008.

[9] C. Zhuo and Y. Levendis, "Upcycling waste plastics into carbon nanomaterials: a review," J. Appl. Polym. Sci., vol. 131, pp. 1 - 14, Feb. 2014.

[10] C. Zhuo, X. Wang, W. Nowak, and Y. Levendis, "Oxidative heat treatment of 316L stainless steel for effective catalytic growth of carbon nanotubes," App. Surf. Sci., vol. 313, pp. 227 - 236, Sep. 2014.

[11] I. Anzel, "High temperature oxidation of metals and alloys," Metalurgija - Journal of Metallurgy, vol. 13, pp. 21 - 26, Jan. 2007.

[12] S. Mopoung, "Occurence of carbon nanotube from banana peel activated carbon mixed with mineral oil," Int. J. Phys. Sci., vol. 6, pp. $1789-1792$, Feb. 2011

[13] P. Hayes and P. Grieveson, "The effects of nucleation and growth on the reduction of $\mathrm{Fe}_{2} \mathrm{O}_{3}$ to $\mathrm{Fe}_{3} \mathrm{O}_{4}$," Mettalurgical Transactions B, vol. 12, pp. $319-326$, Jun. 1981.

[14] A. Skrzetsuka, C. Perri, A. Csato, G. Giordano, D. Vuono and J. Nagy, "Chemically driven printed textile sensors based on graphene and carbon nanotubes," Sensors, vol. 14, pp. 16816 - 16826, Aug. 2014.

[15] Q. Zhang, J. Huang, M. Zhao, W. Qian, and F. Wei, "Carbon nanotube mass production: principles and process," ChemSusChem., vol. 4, pp. $864-889$, Oct. 2011.

[16] J. Sengupta and C. Jacob, "The effect of Fe and Ni catalysts on the growth of multiwalled carbon nanotube using chemical vapor deposition," J. Nanopart. Res., vol. 12, pp. 457 - 465, Jan. 2010.

[17] K.A. Shah, B.A. Tali, "Synthesis of carbon nanotubes by catalytic chemical vapour deposition: a review on carbon sources, catalysts, and substrates," Materials Science in Semiconductor Processing, vol. 41, pp $67-82$, Jan. 2016.

[18] R.T.K. Baker, M.A. Barber, P.S. Harris, F.S. Feates, R.J. Waite, "Nucleation and growth of carbon deposits from the nickle catalyzed decomposition of acetylene," Journal of Catalysis, vol. 26, pp 51 62. Aug. 1971. 